\title{
Zinc oxide and zinc hydroxide formation via aqueous precipitation: Effect of the preparation route and lysozyme addition
}

\author{
Ayben Top*, Hayrullah Çetinkaya \\ Department of Chemical Engineering, İzmir Institute of Technology, Urla-İzmir, 35430, Turkey
}

\section{H I G H L I G H T S}

- Aqueous precipitation products of $\mathrm{Zn}\left(\mathrm{NO}_{3}\right)_{2}$ and $\mathrm{NaOH}$ were prepared.

- Synthesis route and lysozyme addition affected morphology of the products.

- $\varepsilon-\mathrm{Zn}(\mathrm{OH})_{2}, \beta-\mathrm{Zn}(\mathrm{OH})_{2}$, and $\mathrm{ZnO}$ crystal structures were observed.

- Lysozyme-ZnO/Zn(OH $)_{2}$ composites with $\sim 5-20 \%$ lysozyme content were obtained.

\section{A R T I C L E I N F O}

\section{Article history:}

Received 13 February 2015

Received in revised form

20 August 2015

Accepted 10 October 2015

Available online 24 October 2015

\section{Keywords:}

Oxides

Composite materials

Precipitation

Powder diffraction

Electron microscopy

Fourier transform infrared spectroscopy

\section{G R A P H I C A L A B S T R A C T}

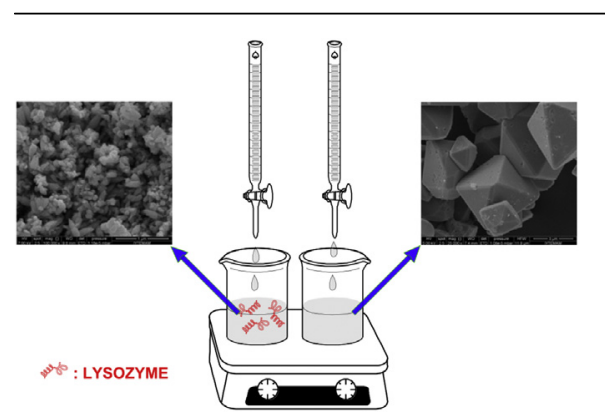

\begin{abstract}
A B S T R A C T
Aqueous precipitation products of $\mathrm{Zn}\left(\mathrm{NO}_{3}\right)_{2}$ and $\mathrm{NaOH}$ obtained by changing the method of combining the reactants and by using lysozyme as an additive were investigated. In the case of single addition method, octahedral $\varepsilon-\mathrm{Zn}(\mathrm{OH})_{2}$ and plate-like $\beta-\mathrm{Zn}(\mathrm{OH})_{2}$ structures formed in the absence and in the presence of lysozyme, respectively. Calcination of these $\mathrm{Zn}(\mathrm{OH})_{2}$ samples at $700{ }^{\circ} \mathrm{C}$ yielded porous $\mathrm{ZnO}$ structures by conserving the template crystals. When zinc source was added dropwise into $\mathrm{NaOH}$ solution, predominantly clover-like $\mathrm{ZnO}$ crystals were obtained independent of lysozyme addition. Mixed spherical and elongated $\mathrm{ZnO}$ morphology was observed when $\mathrm{NaOH}$ was added dropwise into $\mathrm{Zn}\left(\mathrm{NO}_{3}\right)_{2}$ solution containing lysozyme. Lysozyme contents of the precipitation products were estimated as in the range of $\sim 5-20 \%$ and FTIR indicated no significant conformational change of lysozyme in the composite. These results suggest that lysozyme- $\mathrm{ZnO} / \mathrm{Zn}(\mathrm{OH})_{2}$ composite materials may have a value as an antibacterial material.
\end{abstract}

(c) 2015 Elsevier B.V. All rights reserved.

\section{Introduction}

$\mathrm{ZnO}$ is a $\mathrm{II}^{\mathrm{b}}$-VI semiconductor with hexagonal wurtzite type crystal structure and currently in use as a filler/additive in rubber, concrete, and cosmetic industries and as a varistor ceramic in electronic industry. It has a band gap of $3.37 \mathrm{eV}$ at room

\footnotetext{
* Corresponding author.

E-mail address: aybentop@iyte.edu.tr (A. Top).
}

temperature that offers such optoelectronic applications as lightemitting diodes, laser diodes and photodetectors [1-4]. Additionally, $\mathrm{ZnO}$ has a great potential as an electron transport material in solar cells, a gas sensor, and an antibacterial material [4-8]. The size and the structure of $\mathrm{ZnO}$ have strong effect on its physical and chemical properties and hence, its end-use [9]. For example, compared to the rod-shaped particles, hexagonal plate-like $\mathrm{ZnO}$ structures exhibited more than fivefold increase in the photocatalytic activity for the degradation of methylene blue [10]. Similarly, ZnO structures with short nanorod morphology showed 
higher antibacterial activity than long nanorod and nanoplate morphologies [8].

Aqueous precipitation is a widely employed method in the synthesis of $\mathrm{ZnO}$ with different morphologies by simply changing precipitation conditions such as the nature and concentration of zinc source and precipitating agent, $\mathrm{pH}$, temperature, and aging time. Recently, the method of combining the reactants has also been reported to change the morphology [11,12]. For the aqueous precipitation method, different forms of zinc hydroxides, zinc oxide or a mixture of both can be observed depending on the precipitation protocol. Therefore, obtention of the desired precipitation product with desired morphology is perhaps the only challenge of this simple method. The use of additives in aqueous precipitation method as a catalyst and a morphology directing agent has also been successful for providing structural control of the precipitate. A number of additives such as surfactants, and synthetic polymers have been employed to obtain a variety of morphologies including spherical, elongated, hexagonal prismatic, rod-like, ring-like, disklike and sheet-like structures with different dimensions at mild conditions [13-18]. However, macromolecules from biological origin as additives have not been investigated as much as their synthetic counterparts though their promising activities were reported. One of these macromolecules, dextran, directed the formation of flower-like ZnO structures [19]. Likewise, a positively charged polypeptide, poly-L-lysine, was reported to catalyze $\mathrm{ZnO}$ formation at room temperature [20].

Lysozyme is an antibacterial enzyme that can hydrolyze the peptidoglycans in the cell wall of gram-positive bacteria. It was used as a precipitating agent in the synthesis of silica and titania and demonstrated to retain its biological activity in the nanocomposites formed [21]. In this study, it was aimed to test the possibility of preparation of lysozyme containing $\mathrm{Zn}(\mathrm{OH})_{2}$ or $\mathrm{ZnO}$ composites via simple aqueous precipitation route. Precipitation conditions were changed systematically to obtain composites with different chemistry and morphology. The role of lysozyme was deduced by comparing the structures and the morphologies in the presence and absence of lysozyme. Additionally, all the precipitates were calcined to obtain the samples with further changed morphologies.

\section{Materials and methods}

\subsection{Materials}

In the synthesis of the samples, zinc nitrate hexahydrate, $\mathrm{Zn}\left(\mathrm{NO}_{3}\right)_{2} \cdot 6 \mathrm{H}_{2} \mathrm{O}$ (Riedel de Haen, $>98 \%$ ), NaOH (Sigma-Aldrich, 98-100.5\%), and lysozyme from chicken egg white (Fluka, $\sim 70,000 \mathrm{U} / \mathrm{mg}$ ) were used without purification. All the solutions were prepared and washing steps were carried out using deionized water. Potassium bromide, $\mathrm{KBr}$, (Sigma-Aldrich, $\geq 99 \%$, FTIR grade) was used in the preparation of pellets for Fourier transform infrared (FTIR) spectroscopy experiments.

\subsection{Methods}

In a typical experiment, stock solutions of $0.1 \mathrm{M}$ $\mathrm{Zn}\left(\mathrm{NO}_{3}\right)_{2} .6 \mathrm{H}_{2} \mathrm{O}, 0.1 \mathrm{M} \mathrm{Zn}\left(\mathrm{NO}_{3}\right)_{2} .6 \mathrm{H}_{2} \mathrm{O}$ containing $4 \mathrm{mg} / \mathrm{ml}$ lysozyme, $0.2 \mathrm{M} \mathrm{NaOH}$, and $0.2 \mathrm{M} \mathrm{NaOH}$ containing $4 \mathrm{mg} / \mathrm{ml}$ lysozyme were freshly prepared and equal volumes of stagnant solutions (the second column of Table 1) and added solutions (the third column of Table 1) were mixed according to the routes given in Table 1 . It is noteworthy to state that the stock solutions were prepared at the stoichiometric ratio of $\mathrm{Zn}^{2+}$ and $\mathrm{OH}^{-}$. The experiments were carried out using a total solution volume of $240 \mathrm{ml}$. Two different addition procedures were followed: single addition and dropwise addition methods. For the single addition method $120 \mathrm{ml}$ of each solution listed in the last column of Table 1 was poured all onto $120 \mathrm{ml}$ of the relevant stagnant solution at once. In the dropwise addition procedure, on the other hand, the stock solutions were added drop by drop onto the corresponding solutions. The samples were denoted using CX-Y or RX-Y notation in which:

- C corresponds to the samples prepared without lysozyme (control samples) and $\mathrm{R}$ denotes the samples synthesized with the aid of lysozyme,

- $\mathrm{X}$ is the route number used to distinguish stagnant and added solutions and,

- $\mathrm{Y}$ represents the type of addition: $\mathrm{SA}=$ single addition or $\mathrm{DW}=$ dropwise addition.

After combining the reactants, the solutions were stirred continuously at room temperature for overnight. Next, the solutions were centrifuged to get the precipitates. The precipitates were washed with deionized water several times and dried using a vacuum oven at $40{ }^{\circ} \mathrm{C}$ for two days. Finally, some portion of the samples was calcined at $700{ }^{\circ} \mathrm{C}$ for $2 \mathrm{~h}$.

\subsection{Characterization}

Powder X-ray diffraction (XRD) patterns of the samples were obtained using a Philips Xpert-Pro (Panalytical, Almelo, Netherlands) model diffractometer with an incident $\mathrm{CuK}_{\alpha}$ radiation at $1.54 \AA$ A. Crystal phases in the samples were identified qualitatively by using PDF-2 database provided by the International Centre for Diffraction Data (ICDD). The Bragg angle $(2 \theta)$ was ranged between 5 and $80^{\circ}$. FTIR spectra were recorded using an Excalibur FTS 3000 (Digilab, Randolph, MA) model spectrophotometer by employing $\mathrm{KBr}$ disk technique. The spectra were taken between 400 and $4000 \mathrm{~cm}^{-1}$ range with $2 \mathrm{~cm}^{-1}$ resolution. Morphology of the samples was observed using an FEI Quanta 250 FEG (FEI Company, Hillsboro, OR) model scanning electron microscopy (SEM) system. Thermal gravimetric analyses (TGA) of the samples were carried out by employing a Diamond TG-DTA (Perkin Elmer, Waltham, MA) type instrument. Brunauer, Emmett and Teller (BET) surface area values of the samples were determined using physisorption data of nitrogen at $77 \mathrm{~K}$. Physisorption measurements were performed on an ASAP 2010 (Micromeritics, Norcross, GA) model static volumetric adsorption instrument.

\section{Results and discussion}

In order to investigate the effect of the addition of lysozyme and the preparation route on the structure and morphology of the precipitation products, the samples given in Table 1 were synthesized. In addition to changing the addition order of the reactants, the rate of combining of the reactants was also investigated by preparing the samples using both single addition and dropwise addition method.

The first group of samples was synthesized by adding $\mathrm{NaOH}$ solution into stagnant $\mathrm{Zn}\left(\mathrm{NO}_{3}\right)_{2}$ solution. XRD patterns, and SEM pictures of these samples are given in Fig. 1 and Fig. 2a-c, respectively. Conversely, in the synthesis of the second group of samples, $\mathrm{Zn}\left(\mathrm{NO}_{3}\right)_{2}$ solution was added into stagnant $\mathrm{NaOH}$ solution. SEM pictures and XRD patterns of the second group of as-synthesized samples are given in Fig. $2 \mathrm{~d}-\mathrm{f}$ and Fig. 3, respectively. Additionally, lower magnification SEM pictures for the as-synthesized samples are provided in Fig. S1. Crystal structures and morphologies of all the samples are summarized in Table 2. 
Table 1

Preparation routes of the samples.

\begin{tabular}{lll}
\hline Route & Stagnant solution & Added solution \\
\hline C1 & $0.1 \mathrm{M} \mathrm{Zn}\left(\mathrm{NO}_{3}\right)_{2}$ & $0.2 \mathrm{M} \mathrm{NaOH}$ \\
R1 & $0.1 \mathrm{M} \mathrm{Zn(NO})_{2}+4 \mathrm{mg} / \mathrm{ml} \mathrm{Lysozyme}$ & $0.2 \mathrm{M} \mathrm{NaOH}$ \\
R2 & $0.1 \mathrm{M} \mathrm{Zn}\left(\mathrm{NO}_{3}\right)_{2}$ & $0.2 \mathrm{M} \mathrm{NaOH}+4 \mathrm{mg} / \mathrm{ml} \mathrm{Lysozyme}$ \\
C2 & $0.2 \mathrm{M} \mathrm{NaOH}$ & $0.1 \mathrm{M} \mathrm{Zn}\left(\mathrm{NO}_{3}\right)_{2}$ \\
R3 & $0.2 \mathrm{M} \mathrm{NaOH}+4 \mathrm{mg} / \mathrm{ml} \mathrm{Lysozyme}$ & $0.1 \mathrm{M} \mathrm{Zn}\left(\mathrm{NO}_{3}\right)_{2}$ \\
R4 & $0.2 \mathrm{M} \mathrm{NaOH}$ & $0.1 \mathrm{M} \mathrm{Zn(NO})_{2}+4 \mathrm{mg} / \mathrm{ml} \mathrm{Lysozyme}$ \\
\hline
\end{tabular}

XRD peaks at around $2 \theta$ values of mainly 20.1, 20.8, 27.1, 27.7, $32.8,34.8,36.539 .4,40.7,42.0,42.6,52.4,56.0,57.9,59.4$, and $60.3^{\circ}$ were obtained for the samples from the first group prepared in the absence of lysozyme independent of addition rate, C1-SA and C1DW (Fig. 1). This pattern matches very well to the XRD peaks of $\varepsilon-\mathrm{Zn}(\mathrm{OH})_{2}$ sample described by PDF card number of 76-1778 with some differences in the normalized intensity values (Fig. S2). In the SEM pictures of these samples, characteristic octahedral $\varepsilon-\mathrm{Zn}(\mathrm{OH})_{2}$ crystal morphology ranging from a few to several $\mu \mathrm{m}$ was observed (Fig. 2a-i and a-ii) [22]. Of the samples from the second group, this kind of crystal structure was only obtained for the sample prepared in the absence of lysozyme and by single addition protocol (C2-SA).

In aqueous medium, different species form as a function of $\mathrm{pH}$ Yamabi and Imai (2002) observed that $\mathrm{ZnO}$ mainly formed at $\mathrm{pH}$ values between 9 and 13 whereas $\mathrm{Zn}(\mathrm{OH})_{2}$ predominated at $\mathrm{pH}$ 6.0-9.0 [23]. After mixing the reactants the solution $\mathrm{pH}$ values were measured to be less than $~ 8.5$ for the samples C1-SA, C1-DW, and C2-SA consistent with the study of Yamabi and Imai (2002). Similarly, $\varepsilon-\mathrm{Zn}(\mathrm{OH})_{2}$ crystal structure with octahedral morphology was also obtained by dropping $2 \mathrm{M}$ ammonia solution into $1 \mathrm{M}$ zinc acetate solution at $40-50{ }^{\circ} \mathrm{C}$ and $\mathrm{pH}$ 8. Different from the current study, $\varepsilon-\mathrm{Zn}(\mathrm{OH})_{2}$ phase could only be observed at such a high concentration due to the ability of ammonia to dissolve $\varepsilon-\mathrm{Zn}(\mathrm{OH})_{2}[22]$.
When $\mathrm{Zn}\left(\mathrm{NO}_{3}\right)_{2}$ solution was added into $\mathrm{NaOH}$ solution dropwise, on the other hand, a completely different morphology was obtained. As given in Fig. $2 \mathrm{~d}-\mathrm{ii}$, e-ii, and f-ii, predominantly micron size clover like structures formed by the association of nanorods were observed for this group of samples independent of the presence of lysozyme (C2-DW, R3-DW and R4-DW). Though some additional peaks were also identified, these samples had common peaks around $2 \theta$ values of 31.6, 34.2, 36.1, 47.5, 56.4, 62.6, 67.7, and $69.0^{\circ}$ in their XRD patterns (Fig. 3d-f) indicating wurtzite type $\mathrm{ZnO}$ structure given by the PDF card number of 80-0074. $\mathrm{pH}$ values were obtained to be higher than 11 in the early stage of the precipitation of C2-DW as expected. Based on these observations, it can be revealed that one of the accelerators of $\mathrm{ZnO}$ formation is the presence of excess $\mathrm{NaOH}$ (or alkaline conditions) during precipitation. It is not surprising that an alkaline environment catalyzes the formation of $\mathrm{ZnO}$ based on the previous studies [12,23-26]. For example, flake-like $\mathrm{ZnO}$ structures which seem growing over a common nucleus were reported when equal volume of $4 \mathrm{M} \mathrm{NaOH}$ and $0.2 \mathrm{M}$ zinc nitrate were reacted at $60{ }^{\circ} \mathrm{C}[26]$. In another study, ZnO crystals with round and sheet like morphology depending on $\mathrm{OH}^{-1}: \mathrm{Zn}^{2+}$ ratio were obtained at room temperature when $\mathrm{OH}^{-1}: \mathrm{Zn}^{2+}$ ratio was 2.5:1 or higher [12].

In addition to the clover-like $\mathrm{ZnO}$ structures, small amount of
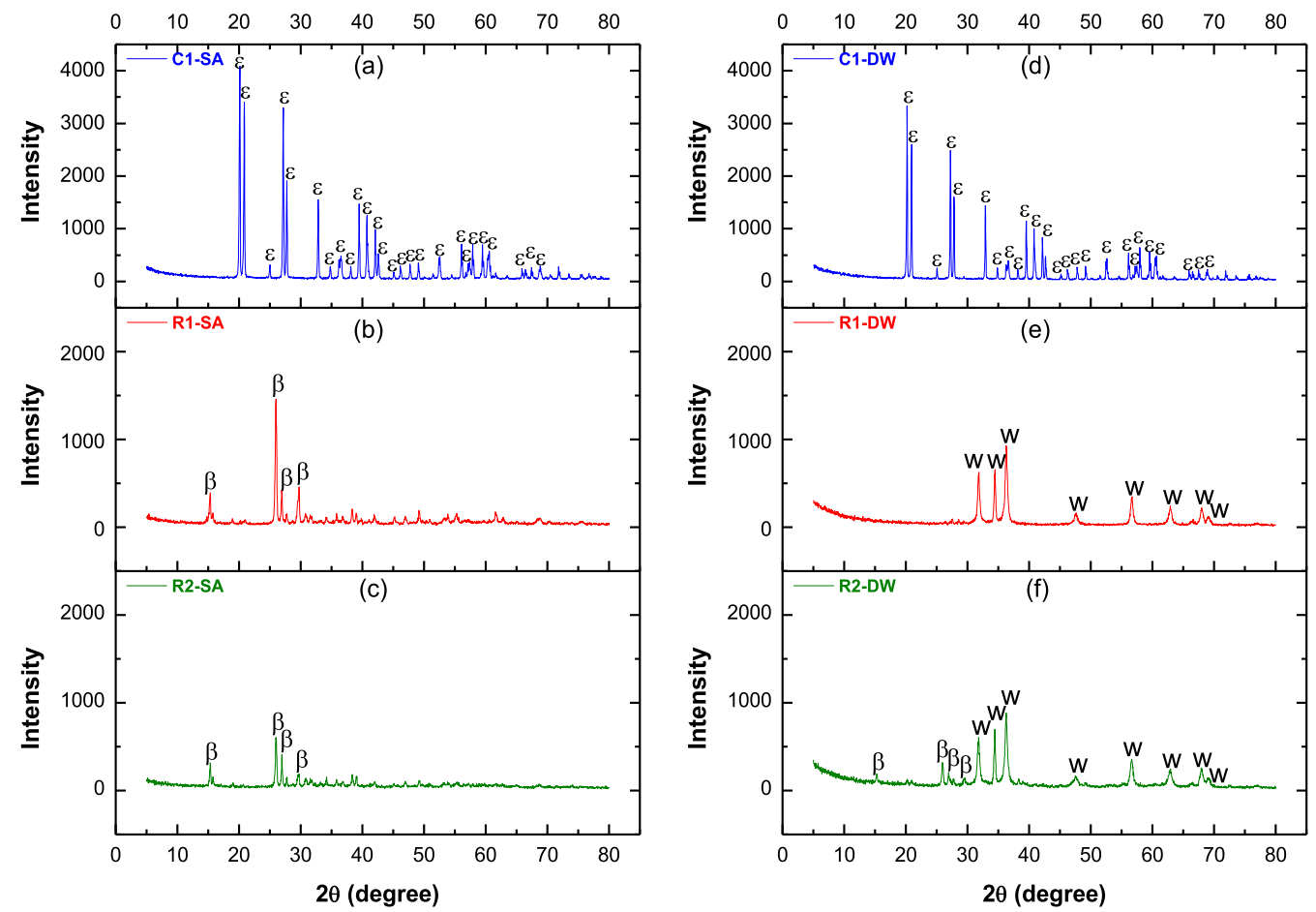

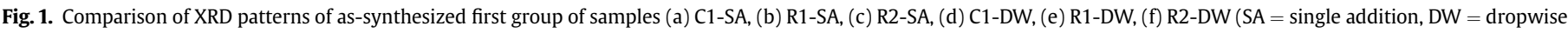
addition). $\varepsilon=\varepsilon-\mathrm{Zn}(\mathrm{OH})_{2}$ with PDF card no: 76-1778; $\beta=\beta-\mathrm{Zn}(\mathrm{OH})_{2}$ with PDF card no: $20-1435$; $\mathrm{w}=$ wurtzite type $\mathrm{ZnO}$ with PDF card no: $80-0074$. 


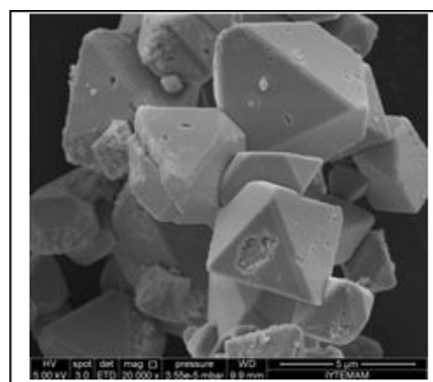

(a-i)

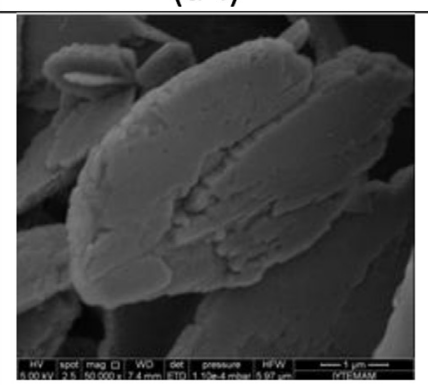

$(b-i)$

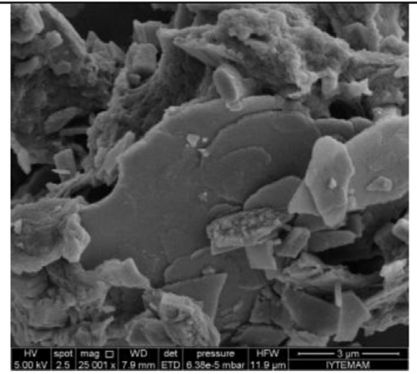

(c-i)

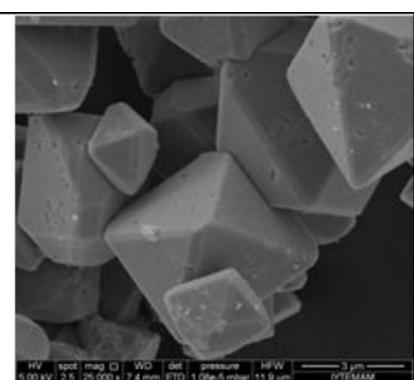

(a-ii)

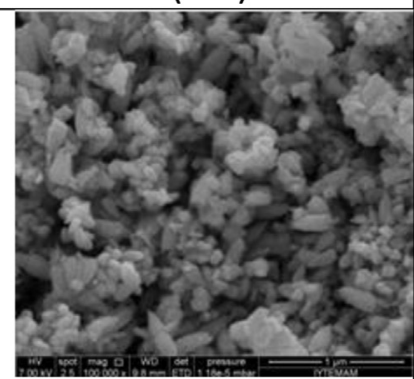

(b-ii)

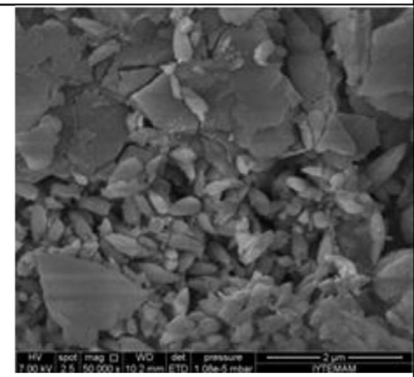

(c-ii)

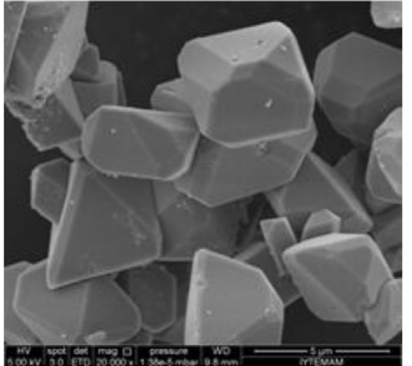

$(d-i)$

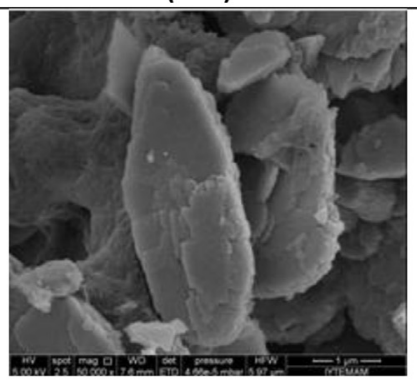

(e-i)

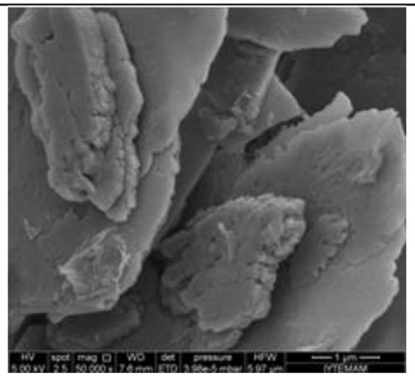

$(f-i)$

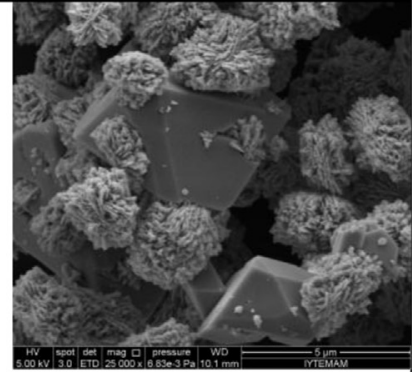

(d-ii)

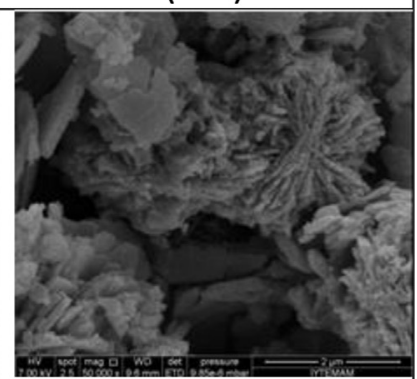

(e-ii)

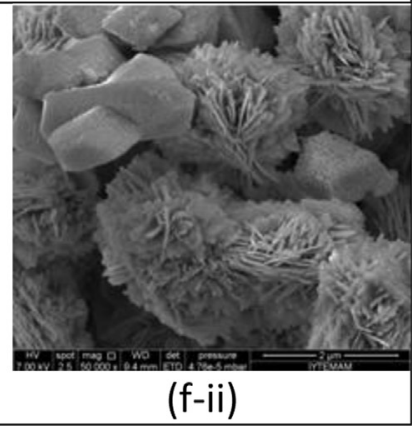

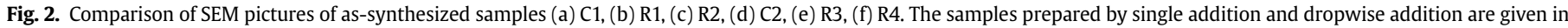
(i) and (ii) respectively. (Scale bars: $a-i, d-i=5 \mu \mathrm{m}, a-i i, c-i=3 \mu \mathrm{m}, c-i i, e-i i, f-i i=2 \mu \mathrm{m}$ and b-i, b-ii, d-ii, e-i, f-i $=1 \mu \mathrm{m}$ ).

plate-like (for R3-DW) and octahedral (for C2-DW and R4-DW) morphologies were also observed. Indeed, plate-like morphology is apparent for the samples prepared using lysozyme in the case of single addition method (R1-SA, R2-SA, R3-SA, R4-SA) as given in Fig. 2. The sample R3-SA presented major peaks at $2 \theta$ values about 15.4, 15.8, 26.0, 27.0, 27.8, 29.6, 30.9, 31.8, 34.2, 36.0, 36.3, 37.0, 38.4, $39.1,42,47.148 .5$ and $49.3^{\circ}$ in its XRD pattern. The peak positions observed for this sample resemble to those of $\beta-\mathrm{Zn}(\mathrm{OH})_{2}$ crystal structure with a PDF card number of 20-1435 (Fig. S3). For the samples R1-SA, R2-SA and R4-SA, the peaks around 15.4, 15.8, 26.0, 27.0 and $29.6^{\circ}$ were observed but the intensity of the rest of the peaks corresponding to $\beta-\mathrm{Zn}(\mathrm{OH})_{2}$ structure did not appear as high as in the XRD pattern of R3-SA. This kind of $\mathrm{Zn}(\mathrm{OH})_{2}$ morphology was mostly observed for layered zinc hydroxides intercalated with organic materials and water molecules. In the layered zinc hydroxides, the layers are positively charged and anions such as sulfate, dodecyl sulfate and nitrate are accommodated within the layers to balance the charge $[17,27-30]$. There are only a few reports in the literature concerning $\beta-\mathrm{Zn}(\mathrm{OH})_{2}$ samples with different XRD patterns. One type of layered $\mathrm{Zn}(\mathrm{OH})_{2}$ was obtained at high temperature and pressure using an $\alpha-\mathrm{Zn}(\mathrm{OH})_{2}$ precursor having layers containing $\mathrm{Zn}^{2+}$ ions [31]. $\mathrm{CdI}_{2}$-type $\mathrm{Zn}(\mathrm{OH})_{2}$ structure with similar lattice parameters was synthesized at mild conditions by mixing zinc nitrate solution and aminoethanol solution followed by aging. The presence of $\mathrm{Zn}^{2+}$ ions in this structure was confirmed by dye adsorption experiments [32]. Another type of $\beta-\mathrm{Zn}(\mathrm{OH})_{2}$ crystal structure with lattice parameters of $\mathrm{a}=13.17 \AA, \mathrm{b}=6.42 \AA$, and $\mathrm{c}=24.1 \AA$ [33] described in PDF card number of 20-1435 has similar XRD pattern as the $\beta-\mathrm{Zn}(\mathrm{OH})_{2}$ crystal structure obtained in the current study. However, more detailed information about this kind of crystal structure is required to comment on the role of lysozyme in the formation of these plate-like structures obtained.

Likewise the second group of samples, dropwise addition in the presence of lysozyme has morphogenic effects for the first group of samples. A mixture of nanosized spherical $(65 \pm 15 \mathrm{~nm})$ and elongated (rice-like, max. width $=95 \pm 20 \mathrm{~nm}$, length $=190 \pm 20 \mathrm{~nm}$ ) ZnO structures was obtained in the SEM picture of R1-DW (Fig. 2b-ii). XRD pattern of this sample matches well to that of the ZnO structure with a PDF card number of 800074 with no other detectable crystal phase (Fig. S4). For the other sample, R2-DW, rice-like $\mathrm{ZnO}$ structures with a length of a few hundred nanometers along with plate-like $\beta-\mathrm{Zn}(\mathrm{OH})_{2}$ morphology were observed (Figs. 1f, 2c-ii). Comparison with the same kind of samples obtained by single addition procedure (with only $\beta$ $\mathrm{Zn}(\mathrm{OH})_{2}$ phase) and small scale experiments at $40 \mathrm{ml}$ total solution volume (having $\beta-\mathrm{Zn}(\mathrm{OH})_{2}$ or mixed $\beta-\mathrm{Zn}(\mathrm{OH})_{2}$ and $\mathrm{ZnO}$ structure) suggests that the use of a large excess of one reactant to the other by allowing a certain exposure time may be inferred to be another ZnO formation accelerator [34].

X-ray crystallography data of bacteriophage T7 lysozyme 

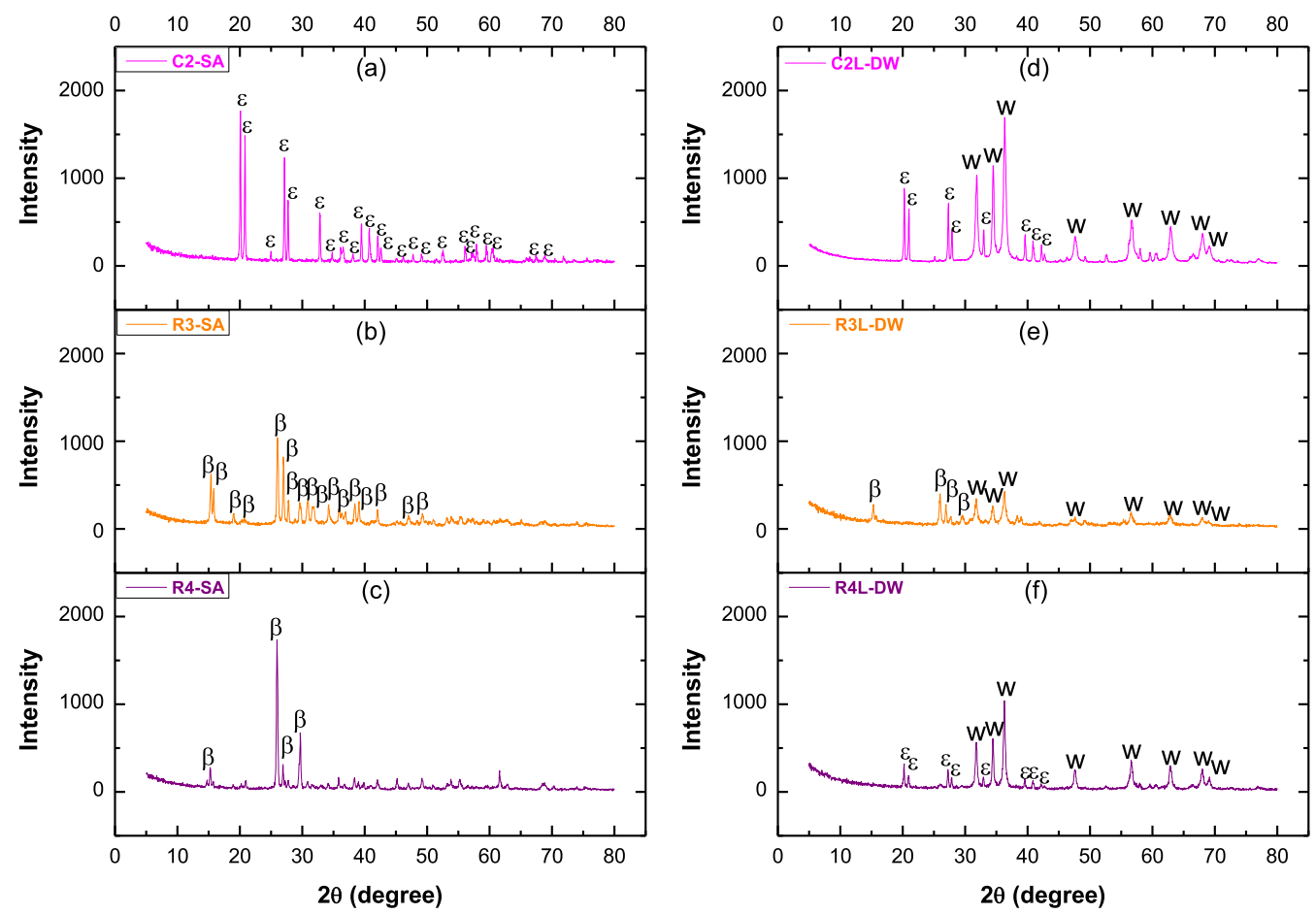

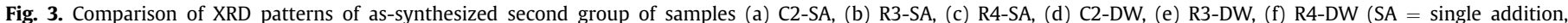
$\mathrm{DW}=$ dropwise addition). $\varepsilon=\varepsilon-\mathrm{Zn}(\mathrm{OH})_{2}$ with PDF card no: 76-1778; $\beta=\beta-\mathrm{Zn}(\mathrm{OH})_{2}$ with PDF card no: 20-1435; w = wurtzite type ZnO with PDF card no: 80-0074.

showed that $\mathrm{Zn}^{2+}$ preferentially binds to histidine and cysteine species. In that study, it was also shown that egg-white lysozyme was able to act as a ligand for zinc [35]. Therefore, the effect of lysozyme seems to control the hydrolysis of $\mathrm{Zn}^{2+}$ species by forming complexes with the cation similar to the action of the other ligands such as ethylenediamine and triethanolamine [34,36]. Considering $\mathrm{ZnO}$ crystal phase was observed for the samples prepared by dropwise addition method only, it is revealed that the presence of lysozyme is not the sole requirement for $\mathrm{ZnO}$ formation. Comparison of $\mathrm{pH}$ profile of the samples R1-DW and R1-SA indicated the same correlation between $\mathrm{pH}$ and crystal structure as observed for the samples prepared in the absence of lysozyme. R1-DW presented basic $\mathrm{pH}$ (between 9.5 and 10.2) after complete addition of $\mathrm{NaOH}$ for $\mathrm{ca} .30 \mathrm{~min}$ and $\mathrm{pH}$ of the solution started to decrease monotonously in the later stage of the precipitation reaction. However, $\mathrm{pH}$ values of R1-SA were obtained to be lower than 8.4 during precipitation similar to the behavior of C1-SA. Thus, different from the samples, R1-SA and C1-SA, the dropwise addition of $\mathrm{OH}^{-}$coupled with the further control of $\mathrm{OH}^{-}$concentration by ionizable amino acids of lysozyme are likely resulted in favor of $\mathrm{ZnO}$ formation for R1-DW. In the case of R2-DW where lysozyme in $\mathrm{NaOH}$ solution is supplied dropwise into zinc source, the presence of small amount of plate-like $\beta-\mathrm{Zn}(\mathrm{OH})_{2}$ phase indicated that a high concentration of lysozyme should be present initially in order to catalyze $\mathrm{ZnO}$ formation. The differences in the XRD patterns and SEM pictures of the as-synthesized samples clearly showed addition of lysozyme, addition order and addition rate of the reactants affected the chemical composition and crystal structure of the precipitation products.

XRD patterns of the calcined samples are given in Fig. 4 and Fig. S5. All of the samples gave similar peaks that correspond to $\mathrm{ZnO}$ structure observed for R1-DW with no detectable $\mathrm{Zn}(\mathrm{OH})_{2}$ structure indicating thermal treatment led to $\mathrm{ZnO}$ formation as expected. SEM pictures of the calcined samples are given in Fig. 5 and Fig. S6. After the calcination, the samples with plate-like and octahedral morphology became porous composed mainly of nanospheres $(\sim 50-200 \mathrm{~nm})$ by preserving template crystal structure as a result of dehydration and subsequent $\mathrm{ZnO}$ formation.

Table 2

Comparison of the crystal structures and morphologies of as-synthesized samples.

\begin{tabular}{|c|c|c|c|c|c|}
\hline \multirow[t]{2}{*}{ Sample } & \multirow[t]{2}{*}{ Stagnant solution } & \multicolumn{2}{|c|}{ Crystal structure by XRD } & \multicolumn{2}{|c|}{ Morphology by SEM } \\
\hline & & Single addition & Dropwise addition & Single addition & Dropwise addition \\
\hline $\mathrm{C} 1$ & $\mathrm{Zn}\left(\mathrm{NO}_{3}\right)_{2}$ & $\varepsilon-\mathrm{Zn}(\mathrm{OH})_{2}$ & $\varepsilon-\mathrm{Zn}(\mathrm{OH})_{2}$ & Octahedral & Octahedral \\
\hline $\mathrm{R} 1$ & & $\beta-\mathrm{Zn}(\mathrm{OH})_{2}$ & $\mathrm{ZnO}$ & Plate-like & $\begin{array}{l}\text { Spherical (major) } \\
\text { rice-like }\end{array}$ \\
\hline $\mathrm{R} 2$ & & $\beta-\mathrm{Zn}(\mathrm{OH})_{2}$ & $\begin{array}{l}\mathrm{ZnO} \text { (major) } \\
\beta-\mathrm{Zn}(\mathrm{OH})_{2}\end{array}$ & Plate-like & $\begin{array}{l}\text { Rice-like } \\
\text { plate-like }\end{array}$ \\
\hline $\mathrm{C} 2$ & $\mathrm{NaOH}$ & $\varepsilon-\mathrm{Zn}(\mathrm{OH})_{2}$ & $\begin{array}{l}\mathrm{ZnO} \text { (major) } \\
\varepsilon-\mathrm{Zn}(\mathrm{OH})_{2}\end{array}$ & Octahedral & $\begin{array}{l}\text { Clover-like (major) } \\
\text { octahedral }\end{array}$ \\
\hline R3 & & $\beta-\mathrm{Zn}(\mathrm{OH})_{2}$ & $\begin{array}{l}\mathrm{ZnO} \\
\beta-\mathrm{Zn}(\mathrm{OH})_{2}\end{array}$ & Plate-like & $\begin{array}{l}\text { Clover-like } \\
\text { plate-like }\end{array}$ \\
\hline R4 & & $\beta-\mathrm{Zn}(\mathrm{OH})_{2}$ & $\begin{array}{l}\mathrm{ZnO} \text { (major) } \\
\varepsilon-\mathrm{Zn}(\mathrm{OH})_{2}\end{array}$ & Plate-like & $\begin{array}{l}\text { Clover-like (major) } \\
\text { octahedral }\end{array}$ \\
\hline
\end{tabular}



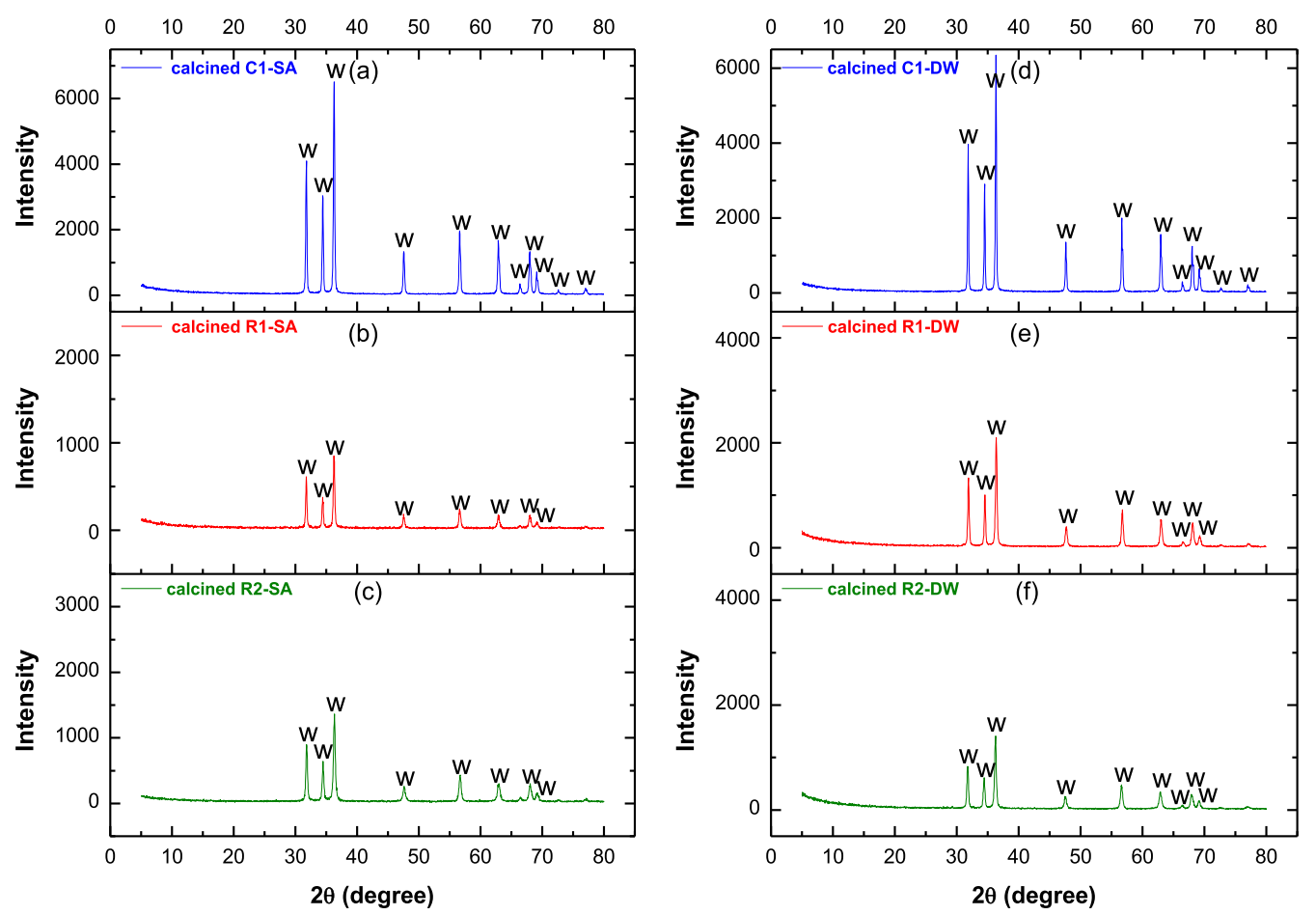

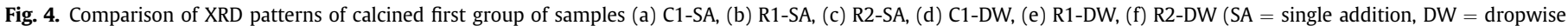
addition). $\mathrm{w}=$ wurtzite type $\mathrm{ZnO}$ with PDF card no: 80-0074.

Porous octahedral morphology of $\mathrm{ZnO}$ composed of spherical nanoparticles was also obtained upon heat treatment of $\varepsilon-\mathrm{Zn}(\mathrm{OH})_{2}$ synthesized using zinc acetate and ammonia precursors [22]. No change in the size of nanosphere and rice-like structures was observed in R1-DW upon heating. These interesting morphologies may offer different application areas. For example, 3D interconnected $\mathrm{ZnO}$ nanoparticles obtained after the calcination of 2D flake-like structures showed promising gas-sensing applications [37,38]. Hence, calcined samples prepared with the aid of lysozyme via single addition method with similar porous sheet-like morphology may have a value in this field.

FTIR spectra of the samples were taken as a complementary method to XRD analyses providing additional information about the incorporation of lysozyme into the precipitation products and its conformational change, if any, during the preparation process. FTIR spectra obtained for as-synthesized first and second group of samples and lysozyme are given in Fig. 6, Fig. 7 and Fig. 8, respectively. FTIR spectra of the calcined samples are shown in Fig. 9 and Fig. S7. In consistent with the XRD data, three of the control samples prepared without lysozyme C1-SA, C2-SA and C1-DW gave identical spectra with major bands around 477, 717, 1029, 1086, and $3240 \mathrm{~cm}^{-1}$, which correspond to the bands observed for $\varepsilon-\mathrm{Zn}(\mathrm{OH})_{2}$ [39]. The band at $477 \mathrm{~cm}^{-1}$ is due to lattice $\mathrm{Zn}-\mathrm{O}$ vibrations, and the two bands around 1029 and $1086 \mathrm{~cm}^{-1}$ describe asymmetric stretching vibrations of $\mathrm{Zn}-\mathrm{O}-\mathrm{Zn}$ bridge oxygen in the orthorhombic structure $[39,40]$. The band at $717 \mathrm{~cm}^{-1}$ can be related to $\delta_{\mathrm{OH}}$ groups. Additionally, hydroxyl group stretching of $\mathrm{Zn}(\mathrm{OH})_{2}$ and physically adsorbed water appears as a broad band between 3000 and $4000 \mathrm{~cm}^{-1}$ centered around $3240 \mathrm{~cm}^{-1}$ [39]. No band around $1385 \mathrm{~cm}^{-1}$ was observed indicating the absence of nitrate ion [41]. Of the samples prepared in the absence of lysozyme, C2-DW presented a considerable decrease in the absorbance values of the bands between 600 and $1200 \mathrm{~cm}^{-1}$ indicating its much lower $\mathrm{Zn}(\mathrm{OH})_{2}$ content. Upon calcination, all the bands except the one corresponding to lattice $\mathrm{Zn}-\mathrm{O}$ vibrations (observed around $\sim 430-450 \mathrm{~cm}^{-1}$ ) disappeared confirming the formation of $\mathrm{ZnO}$ structure $[39,41]$.

In the FTIR spectrum of lysozyme in solid state, characteristic amide bands as a result of peptide bonds were observed (Fig. 8). The major bands are amide VI band, a broad band centered around $555 \mathrm{~cm}^{-1}$, amide II band at $1539 \mathrm{~cm}^{-1}$, amide I band at $1652 \mathrm{~cm}^{-1}$, and amide $A$ band around $3315 \mathrm{~cm}^{-1}$ [42]. FTIR spectra of the samples synthesized using single addition procedure with the aid of lysozyme at room temperature are similar to those observed for the samples prepared without lysozyme having $\varepsilon-\mathrm{Zn}(\mathrm{OH})_{2}$ phase only. However, additional bands that correspond to amide bands of lysozyme were also observed. Although XRD patterns indicated two different polymorphs, $\varepsilon-\mathrm{Zn}(\mathrm{OH})_{2}$ and $\beta-\mathrm{Zn}(\mathrm{OH})_{2}$, no significant differences were observed in the FTIR spectra of the aforementioned samples. The only difference is relative intensities of the three small bands between 600 and $1000 \mathrm{~cm}^{-1}$. FTIR spectra of the rest of the samples prepared by dropwise addition and using lysozyme followed the same correlation with the XRD patterns. Lysozyme bands were also observed in the FTIR spectra of samples synthesized via dropwise addition method with the aid of lysozyme.

These results showed that some portion of lysozyme was incorporated into $\mathrm{Zn}(\mathrm{OH})_{2} / \mathrm{ZnO}$ structure and hence the formation of the organic-inorganic composite materials. The position of amide I band was used to assess secondary structure of lysozyme in the composites qualitatively $[42,43]$. Only a few $\mathrm{cm}^{-1}$ shifts were observed in amide I band (within the range of $1654 \pm 2 \mathrm{~cm}^{-1}$ ) for the precipitation products indicating quite small degree of conformational change of lysozyme upon its incorporation into the inorganic phase. Similarly, amide I band was observed around $1650 \mathrm{~cm}^{-1}$ for both lysozyme and lysozyme immobilized silica confirming conformational stability of lysozyme [44]. In another study, when the mass ratio of lysozyme to zinc oxide nanoparticles was $100: 1$, a small band observed at $1649 \mathrm{~cm}^{-1}$ for free lysozyme associated with random-coil structures of lysozyme was reported 


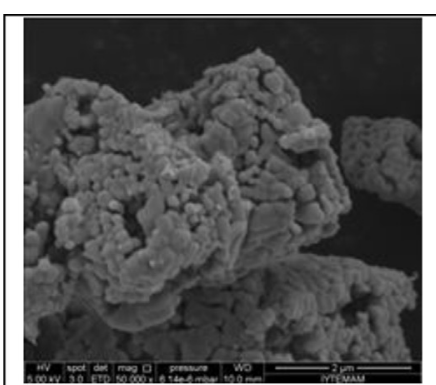

(a-i)

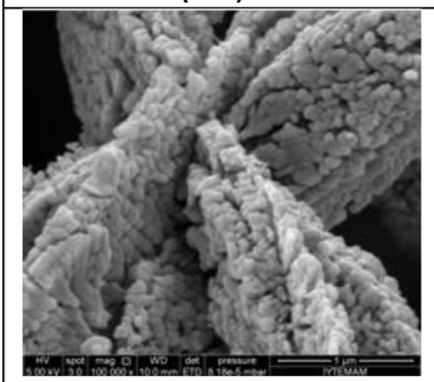

$(b-i)$

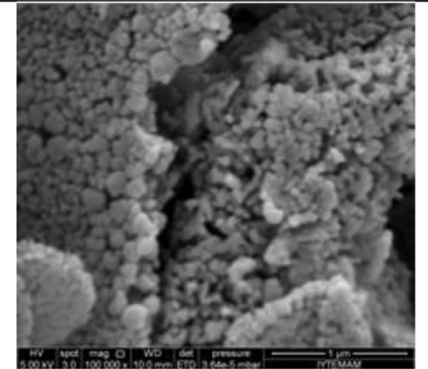

(c-i)

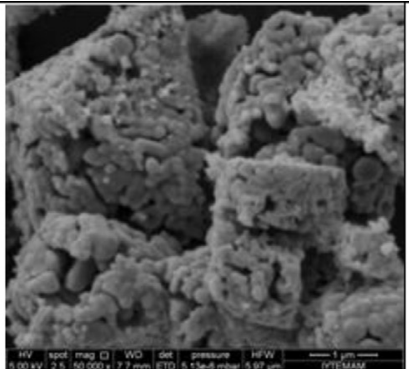

(a-ii)

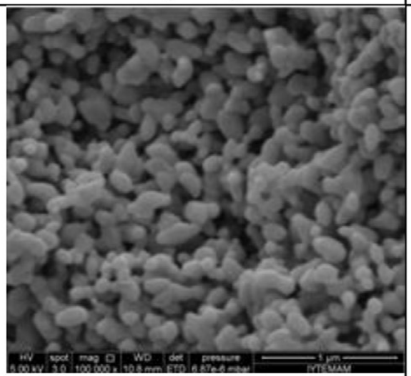

(b-ii)

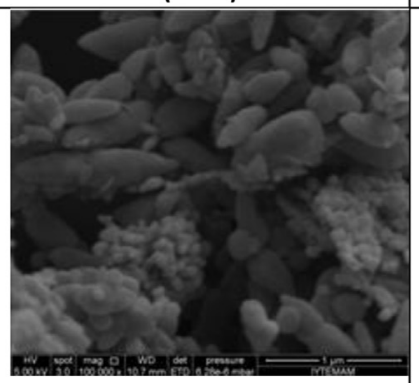

(c-ii)

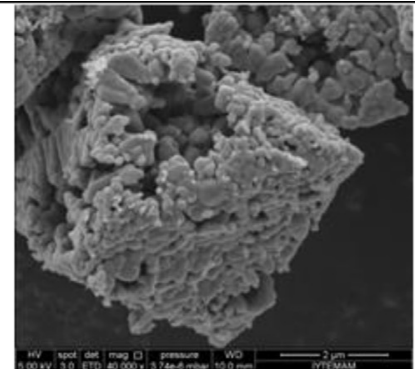

$(d-i)$

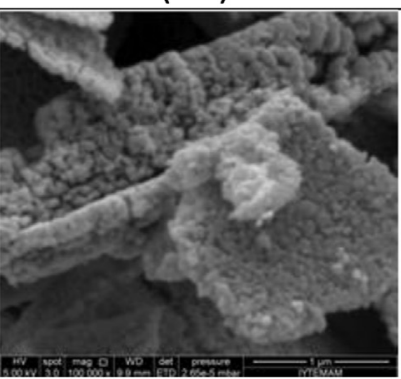

$(e-i)$

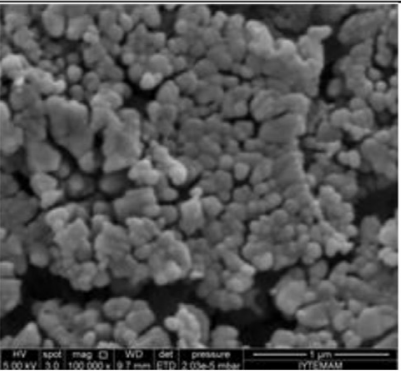

$(f-i)$

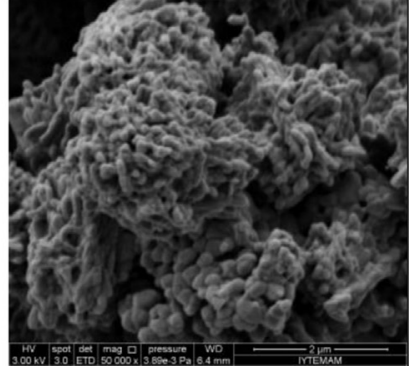

(d-ii)

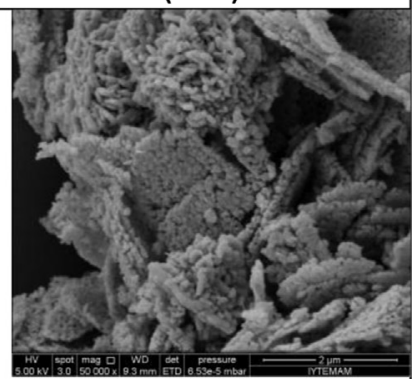

(e-ii)

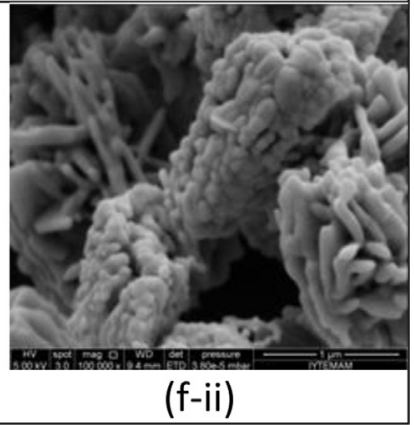

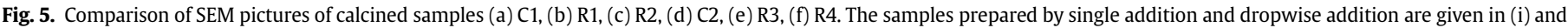
(ii) respectively. (Scale bars: $\mathrm{a}-\mathrm{i}, \mathrm{d}-\mathrm{i}, \mathrm{e}-\mathrm{ii}=2 \mu \mathrm{m}$ and the others $=1 \mu \mathrm{m}$ ).

to disappear as a result of its binding to $\mathrm{ZnO}$ nanoparticles. Additionally, amide I band of free lysozyme centered at $1657.6 \mathrm{~cm}^{-1}$ was observed to shift to $1656.8 \mathrm{~cm}^{-1}$ indicating small alterations in the helical structure of lysozyme upon interaction with the nanoparticles [45]. FTIR spectra of the calcined samples prepared with the aid of lysozyme, are similar to those of the calcined control samples except very small contribution of $\mathrm{OH}$ stretching band independent of the addition rate. Disappearance of amide I and amide II bands indicated almost complete degradation of lysozyme during the heat treatment.

TGA of select samples were taken in order to further confirm the $\mathrm{ZnO}$ formation and to estimate the amount of lysozyme incorporated in to the samples. TGA-DTGA curves of the lysozyme and assynthesized samples prepared by dropwise addition are given in Fig. 10 and Fig. 11, respectively. \% weight loss of the samples at different temperature intervals are summarized in Table 3. Degradation of the lysozyme can be revealed by the two endotherms around $310{ }^{\circ} \mathrm{C}$ and $700{ }^{\circ} \mathrm{C}$ in the DTGA curve. TGA curve of the lysozyme indicated almost complete degradation of lysozyme at $1000{ }^{\circ} \mathrm{C}$ (98\% weight loss). In the DTGA curves of the samples, three different kinds of endotherms were observed. The first one is centered about $55-65{ }^{\circ} \mathrm{C}$ and corresponds to unbound water apparent particularly for R2-DW and R3-DW. The second one was observed between $125{ }^{\circ} \mathrm{C}$ and $145{ }^{\circ} \mathrm{C}$ mainly indicating the decomposition of $\mathrm{Zn}(\mathrm{OH})_{2}$ into $\mathrm{ZnO}[12,46]$. C1-DW with $\varepsilon-\mathrm{Zn}(\mathrm{OH})_{2}$ crystal structure exhibited the highest weight loss and R1-DW with $\mathrm{ZnO}$ structure presented negligible weight loss in this temperature range as expected. The third kind of endotherm which is quite obvious for the samples R2-DW and R3-DW in which lysozyme is premixed with $\mathrm{NaOH}$ solution was obtained between $300{ }^{\circ} \mathrm{C}$ and $400{ }^{\circ} \mathrm{C}$ and is due to the degradation of lysozyme. By taking the weight loss between $180{ }^{\circ} \mathrm{C}$ and $1000{ }^{\circ} \mathrm{C}$ (neglecting surface hydroxyl group removal in this range), it was roughly estimated that these two samples have quite high lysozyme content, above $20 \%$. Thus, it is likely that lysozyme in deprotonated state can be incorporated into $\mathrm{ZnO} / \mathrm{Zn}(\mathrm{OH})_{2}$ structure with a higher extent. Lysozyme content of the other samples (R1-DW and R4-DW) was estimated to be about $5-6 \%$. Considering no significant conformational change of lysozyme observed in FTIR spectra of the samples along with their high lysozyme contents revealed by TGA, it can be inferred that those lysozyme $\mathrm{ZnO} / \mathrm{Zn}(\mathrm{OH})_{2}$ composite materials may present interesting antibacterial properties which should be explored in detail.

BET surface area values of the calcined samples synthesized by dropwise addition are given in Table 4 . Surface areas of the samples synthesized without lysozyme (calcined C1-DW and C2-DW) were measured as quite low $\left(\sim 3 \mathrm{~m}^{2} / \mathrm{g}\right)$. Similarly, in the absence of any additive, the precipitation products of zinc acetate and zinc chloride with $\mathrm{NaOH}$ also exhibited low surface areas, 1 and $6 \mathrm{~m}^{2} / \mathrm{g}$, respectively [47]. The highest surface area values $\left(\sim 8-10 \mathrm{~m}^{2} / \mathrm{g}\right)$ 

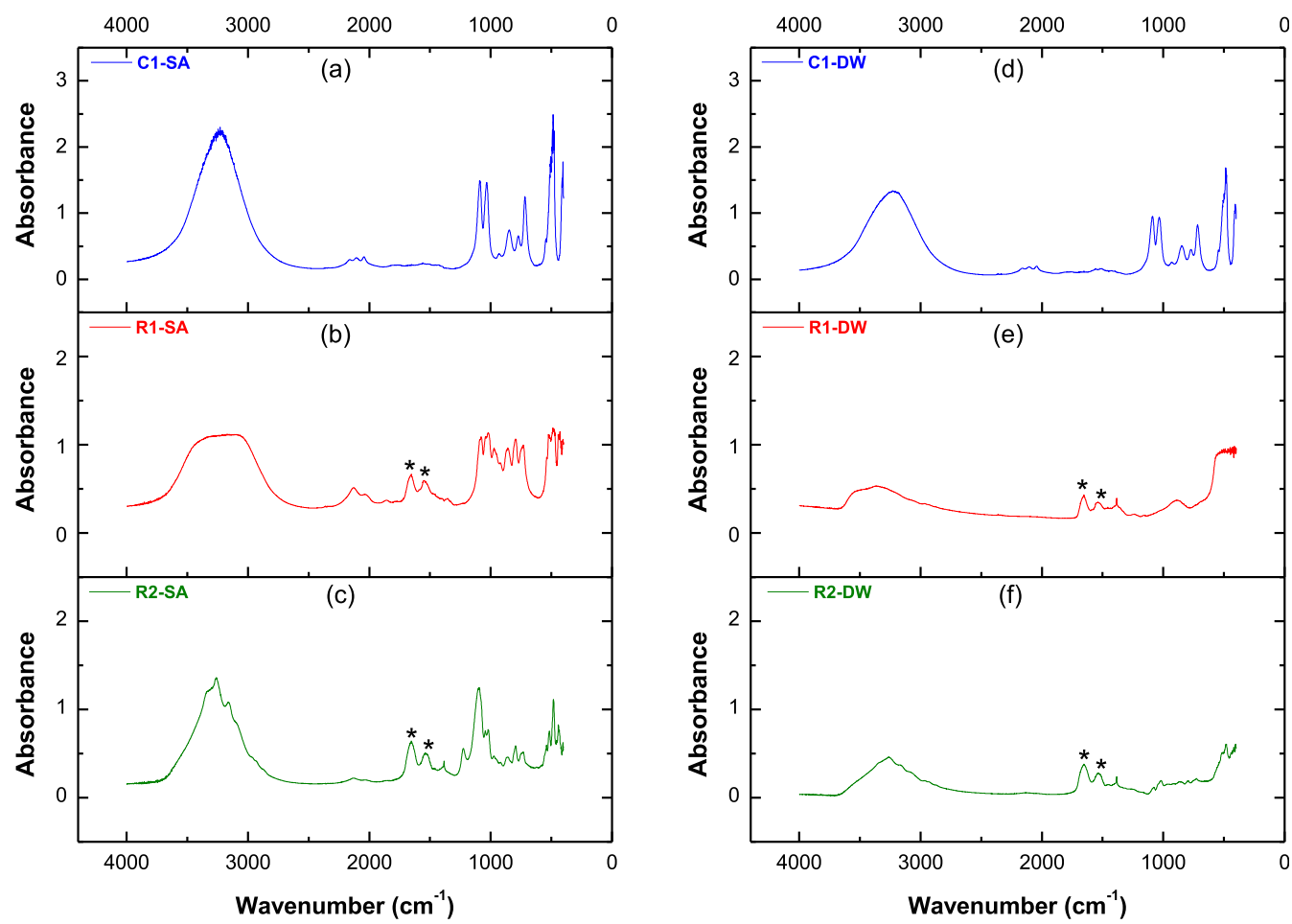

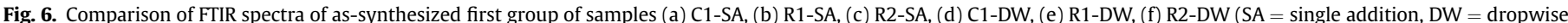
addition).

were obtained for calcined R2-DW and R3-DW likely due to their high lysozyme contents. The use of sucrose and glucose in the synthesis of $\mathrm{ZnO}$ was reported to have significant effect on the surface area of $\mathrm{ZnO}[48,49]$. In the case of sucrose, the surface area of $\mathrm{ZnO}$, synthesized by a reverse microemulsion-based evaporation-induced self-assembly (EISA) technique, increased from $\sim 5 \mathrm{~m}^{2} / \mathrm{g}$ to above $200 \mathrm{~m}^{2} / \mathrm{g}$ when molar ratio of sucrose to $\mathrm{Zn}^{2+}$ was adjusted to 1 [48]. At the same additive to $\mathrm{Zn}^{2+}$ molar ratio ( $\left.\mathrm{R}\right)$, no
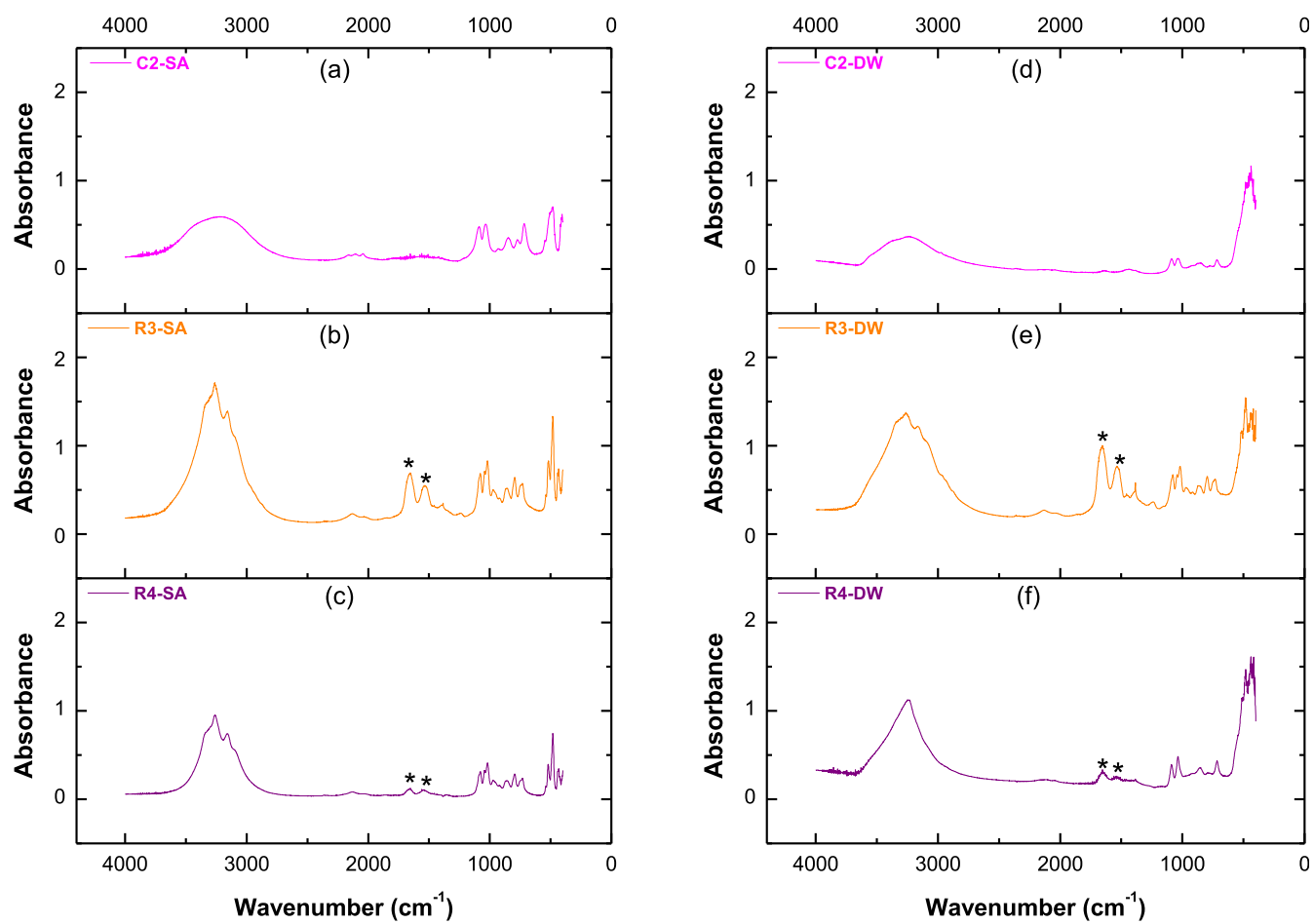

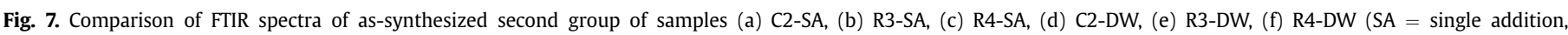
$\mathrm{DW}=$ dropwise addition). 


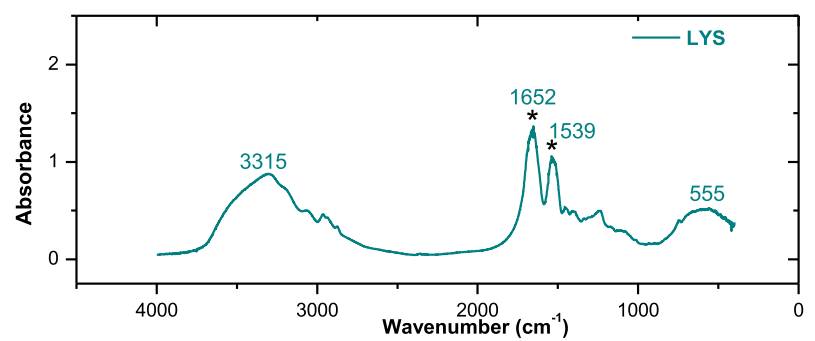

Fig. 8. FTIR spectrum of lysozyme. The symbol, *, shows amide I and amide II bands.

significant change was observed for the surface area of the $\mathrm{ZnO}$ sample, synthesized hydrothermally with glucose additive $\left(7-8 \mathrm{~m}^{2} / \mathrm{g}\right.$ ). However, when $\mathrm{R}$ was increased to 5 , the surface area was obtained as $42 \mathrm{~m}^{2} / \mathrm{g}$ [49]. Though R1-DW and R4-DW have similar amount of lysozyme incorporation, the surface area of R1DW was determined as high as those of R2-DW and R3-DW because of lower particle size of R1-DW. Thus, according to these observations, surface areas of the samples can be tuned by the amount of additive and particle size which can be controlled by the precipitation route and temperature for aqueous preparation procedure.

\section{Conclusions}

Effects of the preparation route and lysozyme addition on the structure and morphology of the precipitation products of stoichiometric amount of zinc nitrate and sodium hydroxide were studied systematically. Crystal morphologies including octahedral $\varepsilon-\mathrm{Zn}(\mathrm{OH})_{2}$, plate-like $\beta-\mathrm{Zn}(\mathrm{OH})_{2}$, clover-like $\mathrm{ZnO}$ and mixture of spherical and elongated $\mathrm{ZnO}$ were obtained. In general, $\varepsilon-\mathrm{Zn}(\mathrm{OH})_{2}$ is obtained in the absence of lysozyme and at nearly neutral to slightly basic $\mathrm{pH}$ range. When initial $\left[\mathrm{OH}^{-}\right]:\left[\mathrm{Zn}^{2+}\right]$ ratio is high as in

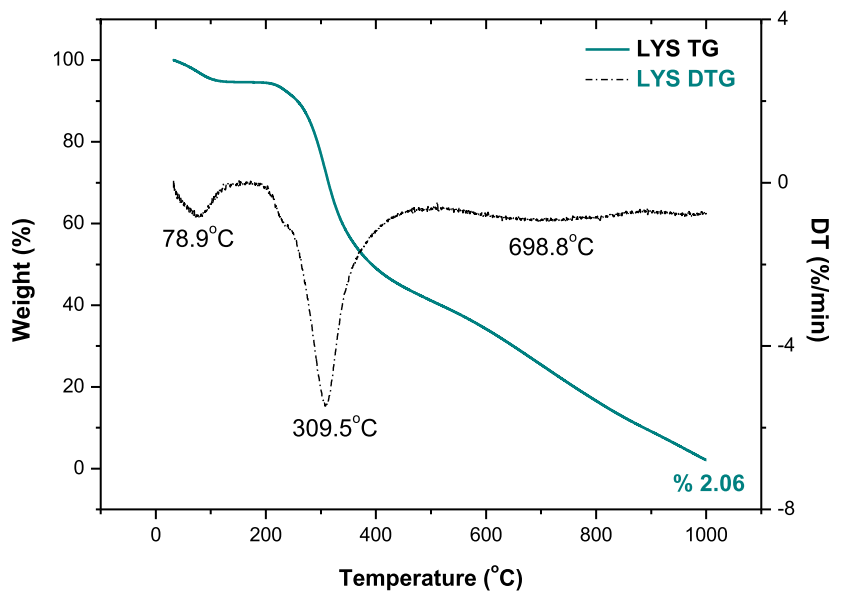

Fig. 10. TGA and DTGA curves of the lysozyme used in the experiments. Solid and broken lines show the TGA and DTGA curves respectively.

the dropwise addition method where $\mathrm{NaOH}$ is stagnant medium, dendritic $\mathrm{ZnO}$ is favored predominantly independent of lysozyme addition.

Lysozyme was found to have both catalytic and morphogenic effects depending on the preparation route. In the case of single addition method, it guides the formation of plate-like structures whereas when it is contained in the stagnant $\mathrm{Zn}\left(\mathrm{NO}_{3}\right)_{2}$ solution and $\mathrm{NaOH}$ is supplied slowly, it catalyzes the formation of $\mathrm{ZnO}$ at room temperature. The inherent antibacterial activity of lysozyme coupled with incorporation of significant amount of lysozyme without significant conformational change suggest that $\mathrm{ZnO} / \mathrm{Zn}(\mathrm{OH})_{2}$-lysozyme composites can be a promising antibacterial material.

Calcination of $\mathrm{Zn}(\mathrm{OH})_{2}$ yielded $\mathrm{ZnO}$ formation as expected. The
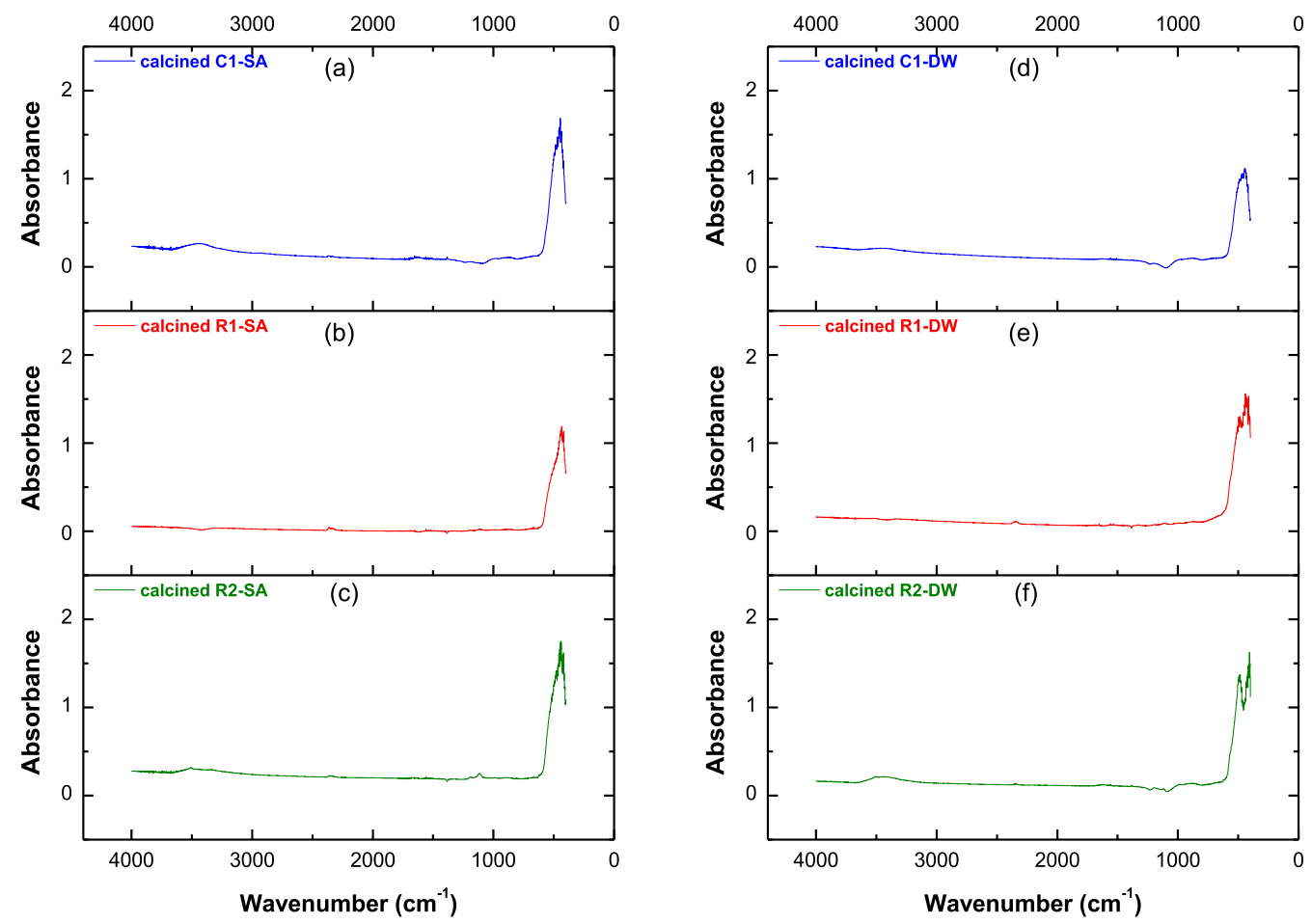

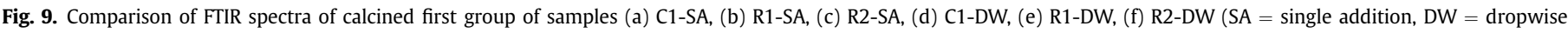
addition). 

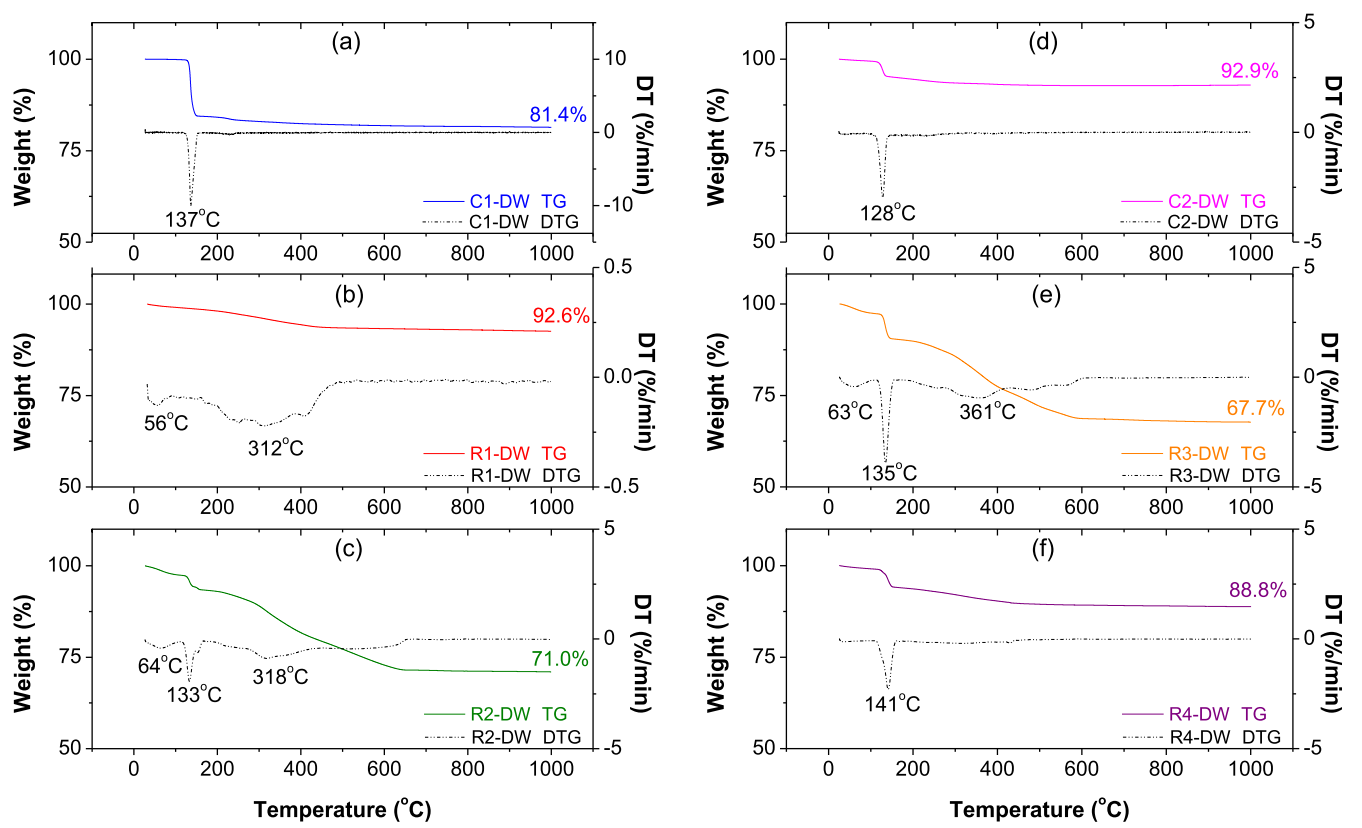

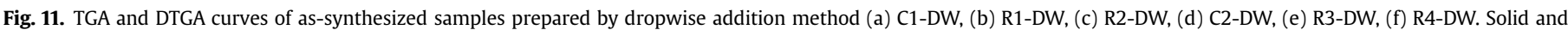
broken lines show TGA and DTGA curves respectively.

Table 3

$\%$ Weight loss values of the as-synthesized samples prepared by dropwise addition.

\begin{tabular}{|c|c|c|c|c|}
\hline Sample & $\%$ Weight loss between $30^{\circ} \mathrm{C}$ and $100{ }^{\circ} \mathrm{C}$ & $\%$ Weight loss between $100{ }^{\circ} \mathrm{C}$ and $180^{\circ} \mathrm{C}$ & $\%$ Weight loss between $180{ }^{\circ} \mathrm{C}$ and $1000{ }^{\circ} \mathrm{C}$ & Total \% weight loss \\
\hline C1-DW & 0.1 & 15.6 & 2.9 & 18.6 \\
\hline R1-DW & 0.9 & 0.8 & 5.8 & 7.4 \\
\hline R2-DW & 2.4 & 4.3 & 22.3 & 29.0 \\
\hline C2-DW & 0.6 & 4.7 & 1.8 & 7.1 \\
\hline R3-DW & 2.5 & 7.4 & 22.4 & 32.3 \\
\hline R4-DW & 0.9 & 5.3 & 5.1 & 11.2 \\
\hline
\end{tabular}

Table 4

BET surface area values of select calcined samples.

\begin{tabular}{lc}
\hline Sample & BET surface area $\left(\mathrm{m}^{2} / \mathrm{g}\right)$ \\
\hline C1-DW & 3.0 \\
C2-DW & 3.2 \\
R1-DW & 7.6 \\
R2-DW & 8.5 \\
R3-DW & 10.6 \\
R4-DW & 4.9 \\
\hline
\end{tabular}

template crystals were preserved and became porous after calcination. Of these morphologies, the plate-like morphology composed of connected nanospheres may have a value in gas sensing application based on the success of the $\mathrm{ZnO}$ structures with similar morphology in this area.

In conclusion, simply changing the preparation route, addition of lysozyme and calcination allowed preparation of $\mathrm{Zn}(\mathrm{OH})_{2}$ and $\mathrm{ZnO}$ samples with different morphologies which may find different application areas.

\section{Acknowledgments}

The authors thank to Material Research Center at Izmir Institute of Technology for making XRD, SEM and TGA experiments possible. Research Specialists Nesrin Gaffaroğlu and Nesrin Tatlıdil are also acknowledged for their helps in FTIR experiments and $\mathrm{N}_{2}$ physisorption measurements, respectively.

\section{Appendix A. Supplementary data}

Supplementary data related to this article can be found at http:// dx.doi.org/10.1016/j.matchemphys.2015.10.013.

\section{References}

[1] C. Klingshirn, ZnO: material, physics and applications, ChemPhysChem 8 (2007) 782-803.

[2] D.R. Clarke, Varistor ceramics, J. Am. Ceram. Soc. 82 (1999) 485-502.

[3] A. Janotti, C.G. Van de Walle, Fundamentals of zinc oxide as a semiconductor, Rep. Prog. Phys. 72 (2009) 126501.

[4] A.B. Djurišić, A.M.C. Ng, X.Y. Chen, ZnO nanostructures for optoelectronics: material properties and device applications, Prog. Quantum Electron. 34 (2010) 191-259.

[5] I. Gonzalez-Valls, M. Lira-Cantu, Vertically-aligned nanostructures of ZnO for excitonic solar cells: a review, Energy Environ. Sci. 2 (2009) 19-34.

[6] G. Eranna, B. Joshi, D. Runthala, R. Gupta, Oxide materials for development of integrated gas sensors-A comprehensive review, Crit. Rev. Solid State Mater. Sci. 29 (2004) 111-188.

[7] K.M. Reddy, K. Feris, J. Bell, D.G. Wingett, C. Hanley, A. Punnoose, Selective toxicity of zinc oxide nanoparticles to prokaryotic and eukaryotic systems, Appl. Phys. Lett. 90 (2007) 213902.

[8] M. Ramani, S. Ponnusamy, C. Muthamizhchelvan, J. Cullen, S. Krishnamurthy, E. Marsili, Morphology-directed synthesis of ZnO nanostructures and their antibacterial activity, Coll. Surf. B 105 (2013) 24-30.

[9] Y. Zhang, J. Mu, Controllable synthesis of flower-and rod-like $\mathrm{ZnO}$ nanostructures by simply tuning the ratio of sodium hydroxide to zinc acetate Nanotechnology 18 (2007) 075606.

[10] A. Mclaren, T. Valdes-Solis, G. Li, S.C. Tsang, Shape and size effects of $\mathrm{ZnO}$ nanocrystals on photocatalytic activity, J. Am. Chem. Soc. 131 (2009) $12540-12541$.

[11] S. Musić, A. Šarić, S. Popović, Dependence of the microstructural properties of ZnO particles on their synthesis, J. Alloy Compd. 448 (2008) 277-283. 
[12] A. Moezzi, M. Cortie, A. McDonagh, Aqueous pathways for the formation of zinc oxide nanoparticles, Dalton T 40 (2011) 4871-4878.

[13] A.P.A. Oliveira, J.F. Hochepied, F. Grillon, M.H. Berger, Controlled precipitation of zinc oxide particles at room temperature, Chem. Mater. 15 (2003) 3202-3207.

[14] H. Usui, The effect of surfactants on the morphology and optical properties of precipitated wurtzite ZnO, Mater. Lett. 63 (2009) 1489-1492.

[15] A. Taubert, D. Palms, Ö. Weiss, M.-T. Piccini, D.N. Batchelder, Polymer-assisted control of particle morphology and particle size of zinc oxide precipitated from aqueous solution, Chem. Mater. 14 (2002) 2594-2601.

[16] Y. Peng, A.W. Xu, B. Deng, M. Antonietti, H. Cölfen, Polymer-controlled crystallization of zinc oxide hexagonal nanorings and disks, J. Phys. Chem. B 110 (2006) 2988-2993.

[17] M.Z. bin Hussein, M.Y. Ghotbi, A.H. Yahaya, M.Z.A. Rahman, The effect of polymers onto the size of zinc layered hydroxide salt and its calcined product, Solid State Sci. 11 (2009) 368-375.

[18] A. Aimable, M.T. Buscaglia, V. Buscaglia, P. Bowen, Polymer-assisted precipitation of $\mathrm{ZnO}$ nanoparticles with narrow particle size distribution, J. Eur Ceram. Soc. 30 (2010) 591-598.

[19] L. Qi, H. Li, L. Dong, Simple synthesis of flower-like ZnO by a dextran assisted solution route and their photocatalytic degradation property, Mater. Lett. 107 (2013) 354-356.

[20] G. Begum, S.V. Manorama, S. Singh, R.K. Rana, Morphology-controlled assembly of $\mathrm{ZnO}$ nanostructures: a bioinspired method and visible luminescence, Chem. Eur. J. 14 (2008) 6421-6427.

[21] H.R. Luckarift, M.B. Dickerson, K.H. Sandhage, J.C. Spain, Rapid, roomtemperature synthesis of antibacterial bionanocomposites of lysozyme with amorphous silica or titania, Small 2 (2006) 640-643.

[22] X.R. Qu, D.C. Jia, Synthesis of octahedral ZnO mesoscale superstructures via thermal decomposing octahedral zinc hydroxide precursors, J. Cryst. Growth 311 (2009) 1223-1228.

[23] S. Yamabi, H. Imai, Growth conditions for wurtzite zinc oxide films in aqueous solutions, J. Mater. Chem. 12 (2002) 3773-3778.

[24] S. Xu, Z.L. Wang, One-dimensional ZnO nanostructures: solution growth and functional properties, Nano Res. 4 (2011) 1013-1098.

[25] J. Zhang, L.D. Sun, J.L. Yin, H.L. Su, C.S. Liao, C.H. Yan, Control of ZnO morphology via a simple solution route, Chem. Mater. 14 (2002) 4172-4177.

[26] S. Sepulveda-Guzman, B. Reeja-Jayan, E. de la Rosa, A. Torres-Castro, V. Gonzalez-Gonzalez, M. Jose-Yacaman, Synthesis of assembled ZnO structures by precipitation method in aqueous media, Mater. Chem. Phys. 115 (2009) 172-178.

[27] O. Altuntasoglu, Y. Matsuda, S. Ida, Y. Matsumoto, Syntheses of zinc oxide and zinc hydroxide single nanosheets, Chem. Mater. 22 (2010) 3158-3164.

[28] J.W. Lee, W.C. Choi, J.D. Kim, Size-controlled layered zinc hydroxide intercalated with dodecyl sulfate: effect of alcohol type on dodecyl sulfate template, Crystengcomm 12 (2010) 3249-3254.

[29] C.H. Liang, Z.F. Tian, T. Tsuruoka, W.P. Cai, N. Koshizaki, Blue and green luminescence from layered zinc hydroxide/dodecyl sulfate hybrid nanosheets, J. Photoch. Photobio. A 224 (2011) 110-115.

[30] S.P. Newman, W. Jones, Comparative study of some layered hydroxide salts containing exchangeable interlayer anions, J. Solid State Chem. 148 (1999) 26-40.

[31] R. Lieth, Preparation and Crystal Growth of Materials with Layered Structures,
Springer, 1977

[32] X. Peng, J. Jin, N. Kobayashi, W. Schmitt, I. Ichinose, Time-dependent growth of zinc hydroxide nanostrands and their crystal structure, Chem. Commun. (2008) 1904-1906.

[33] R. Giovanoli, H. Oswald, W. Feitknecht, Über die thermische zersetzung der kristallinen zinkhydroxide, Helv. Chim. Acta 49 (1966) 1971-1983.

[34] K. Govender, D.S. Boyle, P.B. Kenway, P. O'Brien, Understanding the factors that govern the deposition and morphology of thin films of $\mathrm{ZnO}$ from aqueous solution, J. Mater. Chem. 14 (2004) 2575-2591.

[35] X. Cheng, X. Zhang, J.W. Pflugrath, F.W. Studier, The structure of bacteriophage T7 lysozyme, a zinc amidase and an inhibitor of T7 RNA polymerase, Proc. Natl. Acad. Sci. U. S. A. 91 (1994) 4034-4038.

[36] T. Trindade, J.D.P. de Jesus, P. O'Brien, Preparation of zinc oxide and zinc sulfide powders by controlled precipitation from aqueous solution, J. Mater. Chem. 4 (1994) 1611-1617.

[37] J. Li, H. Fan, X. Jia, Multilayered ZnO nanosheets with 3D porous architectures: synthesis and gas sensing application, J. Phys. Chem. C 114 (2010) 14684-14691.

[38] L. Xue, X. Mei, W. Zhang, L. Yuan, X. Hu, Y. Huang, K. Yanagisawa, Synthesis and assembly of zinc hydroxide sulfate large flakes: application in gas sensor based on a novel surface mount technology, Sens. Actuat. B Chem. 147 (2010) 495-501.

[39] M.Y. Ghotbi, Synthesis and characterization of nano-sized $\varepsilon-\mathrm{Zn}(\mathrm{OH})_{2}$ and its decomposed product, nano-zinc oxide, J. Alloy Compd. 491 (2010) 420-422.

[40] P. Li, Z.P. Xu, M.A. Hampton, D.T. Vu, L.B. Huang, V. Rudolph, A.V. Nguyen, Control preparation of zinc hydroxide nitrate nanocrystals and examination of the chemical and structural stability, J. Phys. Chem. C 116 (2012) 10325-10332.

[41] C. Pholnak, C. Sirisathitkul, D.J. Harding, Characterizations of octahedral zinc oxide synthesized by sonochemical method, J. Phys. Chem. Solids 72 (2011) $817-823$.

[42] J. Kong, S. Yu, Fourier transform infrared spectroscopic analysis of protein secondary structures, Acta Biochim. Biophys. Sin 39 (2007) 549-559.

[43] M. Jackson, H.H. Mantsch, The use and misuse of FTIR spectroscopy in the determination of protein structure, Crit. Rev. Biochem. Mol. 30 (1995) 95-120.

[44] H.M. Ding, L. Shao, R.J. Liu, O.G. Xiao, J.F. Chen, Silica nanotubes for lysozyme immobilization, J. Coll. Interface Sci. 290 (2005) 102-106.

[45] S. Chakraborti, T. Chatterjee, P. Joshi, A. Poddar, B. Bhattacharyya, S.P. Singh, V. Gupta, P. Chakrabarti, Structure and activity of lysozyme on binding to ZnO nanoparticles, Langmuir 26 (2010) 3506-3513.

[46] S. Nistor, D. Ghica, M. Stefan, I. Vlaicu, J. Barascu, C. Bartha, Magnetic defects in crystalline $\mathrm{Zn}(\mathrm{OH})_{2}$ and nanocrystalline $\mathrm{ZnO}$ resulting from its thermal decomposition, J. Alloy Compd. 548 (2013) 222-227.

[47] K. Parida, S. Dash, D. Das, Physico-chemical characterization and photocatalytic activity of zinc oxide prepared by various methods, J. Coll. Interface Sci. 298 (2006) 787-793.

[48] W. Zhang, G. Tu, H. Zhang, Y. Zheng, L. Yang, Synthesis and antibacterial activity of mesoporous zinc oxide particle with high specific surface area, Mater. Lett. 114 (2014) 119-121.

[49] J. Yu, X. Yu, Hydrothermal synthesis and photocatalytic activity of zinc oxide hollow spheres, Environ. Sci. Technol. 42 (2008) 4902-4907. 